\title{
Towards a Cooperation Based Trade Action Agenda
}

After an acquaintance with the market-related determinants of low-carbon technology (LCT) diffusion and highlighting the gaps in the relevant regulatory frameworks in the previous chapter, the question now is that how those gaps may be bridged by creating new opportunities for appropriate responses. Guided by the doctrine of Common Concern of Humankind, this chapter proposes an expansion of the WTO members' responsibility to cooperate to resolve the challenges of LCT diffusion. It begins by pointing out that in purely positivistic terms, the trade rules' falling short of accommodating the interest of LCT diffusion is not illegal per se. It is because even if trade-related actions are potentially conducive to an enabling environment for clean technology diffusion, current wTо rules do not compel members to act in the service of the climate protection goal. It is argued that although the independence of a sovereign to make policy choices is the foundation of international law, refusal or avoidance of cooperation with respect to issues that are of Common Concern can raise questions about the legitimacy of its power to act. Moving towards the goal of creating a coherent framework of technology diffusion actions, this chapter lays out a propositional agenda putting the insights from the Common Concern doctrine to use. It is proposed that cooperation within the trade regime should be preceded by formal recognition of the notion, and would thereupon entail the development of coherent rules of action respecting the principles of equity and differentiation. This is moulded into a new proposed narrative to guide trade policy measures for LCT diffusion. Finally, possible ways of implementing the narrative by taking appropriate steps at the multilateral, regional, and domestic levels are explored.

\section{‘Common Concern' as a Guide to Trade Cooperation}

The desirability of trade measures to support climate action is a well-visited topic in scholarly literature. In contributions dealing with the issue, the response is somewhat dichotomous. While many call for the trade regime's 
involvement, ${ }^{528}$ scepticism also exists. ${ }^{529}$ Brunnée, for example, highlights that the climate regime has over time evolved into a complex prevention mechanism based on non-adversariality and flexible compliance, ${ }^{530}$ making it incompatible with the strict rule-enforcement approach found in the trade regime. Despite the contrasting takes, the search for a path towards stronger trade actions in the service of climate goals is worthwhile for a number of reasons described below.

First of all, the need to facilitate clean technology diffusion is urgent, immediate, and unavoidable, as already articulated. ${ }^{531}$ Second, outright refusals to multilaterally address the trade-related issues involved in LCT diffusion at the WTO would not prevent the deployment of climate-motivated unilateral trade measures. In the absence of multilateral efforts, this issue would be relegated entirely to the domestic level, where it would be subjected to varying interests and conflicting approaches in different jurisdictions. The resulting multiplicity would end up being more burdensome for the developing countries on one hand, and threaten the predictability and transparency of the global trade rule system on the other. Third, much of the dichotomous difference between the trade and the climate rules may only be 'imaginary', leading to no big legal conflicts at the operational levels. ${ }^{32}$ With the quasi-universal participation of states in both regimes and the common subscription to the goal of sustainable

$5_{28}$ Frédéric Simon, 'Stiglitz Urges Joint EU-China Trade Sanctions against the US on Climate Change' (euractiv.com, 28 March 2019) <https://www.euractiv.com/section/climateenvironment/news/stiglitz-urges-joint-eu-china-trade-sanctions-against-the-us-onclimate-change/> accessed 25 October 2020; Paul Sammon, 'Could the Threat of Carbon Tariffs Save the Paris Agreement?' (18 September 2018) <https://ictsd.iisd.org/opinion/ could-the-threat-of-carbon-tariffs-save-the-paris-agreement> accessed 25 October 2020; Scott Barrett and Robert Stavins, 'Increasing Participation and Compliance in International Climate Change Agreements' (2003) 3 International Environmental Agreements: Politics, Law and Economics 349; S Barrett, 'Climate Treaties and the Imperative of Enforcement' (2008) 24 Oxford Review of Economic Policy 239.

529 See, for example, Alexandra E Cirone and Johannes Urpelainen, 'Trade Sanctions in International Environmental Policy: Deterring or Encouraging Free Riding?' (2013) 30 Conflict Management and Peace Science 309.

530 Brunnée, 'MEAs and Complex Prevention' (n 330); Brunnée, 'The Global Climate Regime' (n 159); Jutta Brunnée, 'Enforcement Mechanisms in International Law and International Environmental Law' in Ulrich Beyerlin, Peter-Tobias Stoll and Rudiger Wolfrum (eds), Ensuring compliance with multilateral environmental agreements: a dialogue betweeen practitioners and Academia (Martinus Nijhoff Publishers 2006).

531 See Chapter 1 II A at p. 13 above.

532 Kati Kulovesi, 'Real or Imagined Controversies-a Climate Law Perspective on the Growing Links between the International Trade and Climate Change Regimes' (2014) 6 Trade L. \& Dev. 55 . 
development, it is counterintuitive to assume that commitments made in one regime should conflict with those in others. ${ }^{533}$ Fourth, restrictions are not the only tool in the trade regime's repertoire of possible measures supporting climate change. Trade-related measures can be supportive or facilitative in nature as well. ${ }^{534}$ In the absence of any overarching regulation, states gravitate towards trade restrictions as a function of the current realpolitik, as those measures entail imposing costs on others while incurring none. Finally, while it may be true that the enforcement of climate commitments through trade sanctions could result in unwanted entanglements of compliance actions between the legal regimes, if negotiated climate-related commitments are part of the multilateral trade rules, there shall be no objection to taking recourse to dispute settlement.

The following paragraphs outline the practical considerations regarding the development of such trade commitments.

\section{A The Challenge of Cooperation and Common Concern Doctrine}

The actual existence of a state's responsibility to act in pursuance of shared interests in an issue area has a close, often a causal relationship with the prior existence, nature, and success of international cooperation in that regard. However, even though a long time has passed since Wolfgang Friedmann pointed out international law's gradual turn towards cooperation at different levels, ${ }^{535}$ a duty to cooperate is not a commonplace occurrence yet.

533 We note also the argument made by Broude, holding that complexity is pervasive in all systems, and it is not unique to international law. As a result complexity in itself ought not be the dissuading factor leading a subject-matter to escape the domain of international law. Tomer Broude, 'Complexity Rules (or: Ruling Complexity), a Response to Jutta Brunnée' (Social Science Research Network 2017) SSRN Scholarly Paper ID 3075798 <https://papers. ssrn.com/abstract $=3075798>$ accessed 25 October 2020 .

534 Some authors focus on a 'carrot and stick' balance when introducing trade measures' support. See, for example, Tracey Epps and Andrew Green, Reconciling Trade and Climate: How the WTO Can Help Address Climate Change (Edward Elgar 2010); Andrew Green and Tracey Epps, 'Is There a Role for Trade Measures in Addressing Climate Change?' (2008) 15 31; Aaditya Mattoo and Arvind Subramanian, A 'Greenprint' for International Cooperation on Climate Change (The World Bank 2013) <http://elibrary.worldbank.org/doi/book/10.1596/ 1813-945o-6440> accessed 25 October 2020; Barrett and Stavins (n 530); Gabrielle Zoe Marceau, 'The Interface between the Trade Rules and Climate Change Actions' in DeokYoung Park (ed), Legal Issues on Climate Change and International Trade Law (Springer 2016). For extensive treatment of the topic, see, Thomas Cottier, Olga Nartova and Sadeq $Z$ Bigdeli (eds), International Trade Regulation and the Mitigation of Climate Change: World Trade Forum (Cambridge University Press 20o9); Tamiotti, World Trade Organization and United Nations Environment Programme (n 73).

535 Wolfgang Friedmann, The Changing Structure of International Law (Stevens \& Sons 1964) 61-63. 
Cooperation is almost always voluntary in international affairs, subject to the consent of a state as custodian of the sovereign authority. This comes out clearly in the Charter of the United Nations. While one of the purposes of the UN is to achieve international cooperation in solving economic, social, cultural, and humanitarian problems, ${ }^{536}$ the key principles the organisation abides by are, inter alia, respect for sovereign equality and political independence of the member states. 537

As a result of the above, duties of cooperation can mostly be found in limited constellations of consent-based regulatory frameworks (e.g. treaties), which address shared interests of both economic and non-economic nature. These duties arise due to the interdependent nature of the issues needing to be regulated, requiring reciprocity instead of wilful action by individual states. The legal regime of international trade is such an area. The trade regime is premised upon interdependence rather than independence of nations in their economic relations. ${ }^{538}$ Thomas Cottier also highlighted that international trade rules make a reciprocal regime; one that is built around a quid pro quo exchange of commitments of economic interest for all the parties involved. ${ }^{539}$ In the core of the multilateral trade rules, there is an obligation to negotiate in good faith, binding all the parties to engage in interaction without the constraints of reaching a final outcome. ${ }^{540}$

Duties of cooperation, when arising within treaty frameworks, are also circumscribed by the same. Such a duty tends to pertain only to the subjectmatter that is of interest to the treaty. This holds true for the trade regime. The duty to negotiate and consult in the Wто law does not extend to fringe interactions which form the essence of 'trade and ...' issues, e.g. labour rights or animal welfare, unless it is formally extended by agreement. Similarly, while there is a duty to cooperate in the climate regime arising from the legal recognition of the problem as a common concern of humankind, it does not automatically extend to the legal realm of trade. This disconnect is a product of fragmentation, as was detailed in the first chapter. We recall the proposition that a constitutionalist frame is best suited to anticipate such fragmentation and respond to it based on existing and new meta-norms, i.e. legal principles that can guide separate rule systems to mesh and integrate. ${ }^{541}$ This is the primary role of the

536 Article 1(3) Charter of the United Nations 1945 (1 UNTS XVI).

537 Article 2, ibid.

538 Donald McRae, The Contribution of International Trade Law to the Development of International Law, vol 26o (The Hague Academy of International Law 1994) 111.

539 Cottier, 'The Principle of Common Concern of Humankind' ( $\left.\mathrm{n}_{7}\right)$.

540 Cottier and Payosova (n 169) 15.

541 See Chapter 1 III D at pp. 27-28 above. Also, Ernst-Ulrich Petersmann, 'From Negative to Positive Integration in the wTO: Time for Mainstreaming Human Rights into WTO 
Common Concern of Humankind doctrine. With respect to LCT diffusion and trade, the doctrine is an addition to the underlying framework of principles in the trade regime, helping to launch and sustain an expanded cooperation agenda therein.

It should also be recalled at this point that the principle of sustainable development is already a mainstay of the trade regime, providing a foundational basis for 'trade and ...' integration. ${ }^{542}$ However, even when the principle is given its fullest expression, it would suffice to create space for ex post legitimation and not serve as the basis for an ex ante demand. But making a demand that countries act ex ante, is the essence of a pre-existing duty to cooperate. ${ }^{543} \mathrm{To}$ clarify, the principle of sustainable development does not go so far as to put an actor under a strict positive responsibility to act in stopping climate change. Pursuant to the doctrine of Common Concern, the discourse is framed as such that it goes beyond the question of what states 'may' or 'could' do to prevent climate change. It rather points out what states 'must' do to that end. ${ }^{544}$ For any such deliberation to take place to that effect at the multilateral stage, the essential precondition is having a duty to cooperate in place.

Leaving the defined boundaries of trade cooperation to outline how a state 'shall' or 'must' act would appear to go against the grain of the fundamental international law rule of coexistence, marked by the respect for sovereignty and political independence, as initially indicated. In response, we take the line of argument that understanding sovereignty as an exclusive power monopoly wielded by a government is an outdated approach. John Jackson correctly pointed out that if sovereignty is understood in terms of its core function, i.e. allocation of power, the changing fundamentals of world affairs do indeed require a departure from the traditional understanding. ${ }^{545}$ Sovereigntymodern, as Jackson termed it, calls for a rebalancing of the power exclusivity of each state based on proportionality and subsidiarity, among other things. ${ }^{546}$ This line of thought would challenge the exclusive dependency upon states'

Law' (200o) 37 Common Market L. Rev. 1363; Thomas Cottier and Panagiotis Delimatsis (eds), The Prospects of International Trade Regulation: From Fragmentation to Coherence (Cambridge University Press 2011).

542 Voigt (n 209).

543 See pp. $27-28$ above.

544 Krista Nadakavukaren Schefer and Pablo Arnaiz, 'Duty to Protect, Climate Change and Trade' in Panagiotis Delimatsis (ed), Research handbook on climate change and trade law (Edward Elgar 2016).

545 John Howard Jackson, 'Sovereignty-Modern: A New Approach to an Outdated Concept', Sovereignty, the WTO and changing fundamentals of international law (Cambridge University Press 2006).

546 ibid $71-78$. 
consent in determining whether trade rules ought to be employed for climate protection. We can also consider the argument of Schefer and Arnaiz in the following terms:

[S]ince the consequences of climate change on certain populations is expected to be serious enough to be of concern to the international community as a whole, states will have a duty to take any steps necessary to prevent realization of these threats to the extent possible, [...]. Given the inextricable connections between trade and climate change, as well as the likelihood of any mitigation and adaptation efforts affecting trade, the trade law system must be incorporated into any responsibility framework. ${ }^{547}$

However, recourse to the doctrine of Common Concern does not mean abandonment of the respect for sovereignty principle altogether. It rather necessitates updating our terms of understanding the notion. In areas marked by interdependence, a sovereign's goals of self-determination and public welfare inherently requires that the authority is exercised in cooperation. ${ }^{548}$ Thomas Cottier holds:

As the principle of Common Concern seeks to prevent or remedy threats to international peace, security and welfare in a broader sense, the purpose is in line with the original goals of sovereignty enabling to maintain law and order, provide peace and welfare, and prosperity in society. The principle of Common Concern of Humankind thus complements the same goals aspired by self-determination and enters the stage where these very goals cannot be secured by States alone but depend upon international cooperation. Common Concern helps us to reshape and understand the proper functions of contemporary modern sovereignty. We

547 Schefer and Arnaiz (n 544) 67-68.

548 Samantha Besson, 'Sovereignty in Conflict' (2004) 8 European Integration Online Papers <https://papers.ssrn.com/abstract=594942> accessed 25 October 2020; Franz Xaver Perrez, 'Efficiency of Cooperation: A Functional Analysis of Sovereignty' (1998) 15 Arizona Journal of International and Comparative Law 515; For a deeper take on the relation between Common Concern doctrine and pemanent sovereignty, see, Cottier, 'The Principle of Common Concern of Humankind' (n 7); Also, Alexander Beyleveld, 'Exploring the Recognition of New Common Concerns of Humankind: The Example of the Distribution of Income and Wealth within States' in Thomas Cottier (ed), The Prospects of Common Concern of Humankind in International law (Cambridge University Press 2021). 
can perceive it as a dialogue between the two concepts, influencing each other in shaping and coordinating their respective contours. ${ }^{549}$

Of course, despite the salience of the argument qualifying the exclusive nature of the notion of sovereignty, an unconditional responsibility to cooperate is not practical. As much as trade cooperation would be necessary, so would it be necessary to appropriately delimit its scope. The limits of the influence of the Common Concern doctrine upon the trade regime, as detailed earlier,, 550 would come into play in this regard.

Over the past number of years, there have been many well-thought out propositions on the type of appropriate trade actions that would contribute to climate mitigation as well as the transfer of LCT s. ${ }^{551}$ In comparison, very little work has been done on advancing a formal basis on which such propositions of positive actions could take root in the WTO law and practice. ${ }^{552}$ Citing the example of fisheries subsidies negotiation, Margaret Young astutely suggested that the interaction between trade and climate regimes must be, inter alia, based on principles underlying the climate regime. ${ }^{553}$ While it sounds like a lucrative proposition, it should be noted that regulation of fisheries subsidies is explicitly mandated to the WTO through the sustainable development goals (SDG s). No such mandate has so far been assigned to the wTO regarding climate change. 554

The proposed doctrine of Common Concern can compel the undertaking of effective trade policy responses to the climate crisis. By so doing, it will serve

549 Cottier, 'The Principle of Common Concern of Humankind' ( $n$ 7) s 1.4.4.

550 See Chapter 1 vi at pp. 47-48 above.

551 See for example, Ricardo Melendez-Ortiz and Mahesh Sugathan, 'Enabling the Energy Transition and Scale-Up of Clean Energy Technologies: Options for the Global Trade System - Synthesis of the Policy Options' (2017) 51 933; James Bacchus, 'Global Rules for Mutually Supportive and Reinforcing Trade and Climate Regimes' (International Centre for Trade and Sustainable Development (ICTSD), World Economic Forum (WEF) 2017); Mattoo and Subramanian (n 534); Gary Clyde Hufbauer, Steve Charnovitz and Jisun Kim, Global Warming and the World Trading System (Peterson Institute for International Economics 2009).

$55^{2}$ Except, of course, the work done surrounding the doctrine of Common Concern by Thomas Cottier and others.

553 Margaret A Young, 'Climate Change Law and Regime Interaction' [2011] Carbon \& Climate Law Review 12. However, one point is that unlike climate change the sustainable development goals (SDG S) explicitly mandates the wTo to deliver upon fisheries subsidies regulation.

554 Instead, as noted before, there are examples of conscious efforts by Members to keep the two regimes separated. See, Chapter 2 IV B (ii) at pp. 97-100. 
as a convenient framework to mainstream the existing propositions. It would also enhance the legitimacy of the WTO in a constitutionalist legal order. ${ }^{555}$ It is without any doubt that the states already have the obligation to resolve the common concern of climate change. What remains to be done still is an express and effective foregrounding of that obligation in the domain of trade law. The Common Concern doctrine is well-equipped to do that. The proposed doctrine will serve as the formal basis to grant an enhanced mandate to the WтO for working in the interface area of trade and climate change and to determine the terms of its deeper interaction with the climate governance institutions.

Before moving to the next point, we must admit that confining the discussion of Common Concern inspired cooperation only to that between states is limiting in a sense. We recognise that for the diffusion of LCT, cooperation must also influence other levels of governance, e.g. cities, and include actors other than the state, e.g. research collaboration between firms and universities. Nevertheless, international cooperation is a good starting point for the discussion. It is also influential to bring about broader cooperation.

\section{B Key Issues Regarding a Novel Duty to Cooperate}

Following up on the argument that the doctrine of Common Concern is well poised to be placed within the trade law domain to fill the absence of a duty towards positive cooperation, here we outline the key points of such an endeavour. To recap, as the legal paradigm of Common Concern demands for adequate preventive and remedial actions to be taken, the duty to cooperate arising therefrom obliges the involved parties to look for and adopt the best possible means of doing so. Put in the context of international trade regulation, the doctrine would demarcate in clear terms the reach of the exclusive policy autonomy of sovereign states. ${ }^{556}$ A potential delineation of such manner has a twofold impact. On one hand, a well-defined domain of interdependent action in the trade regime serves as a better rallying point around which the governments can pursue meaningful mutual engagement in good faith to tackle the identified gaps in the trade and climate policy. ${ }^{557}$ On the other hand, absence of any bearing of an issue to a known Common Concern serves to reinforce its

555 Cottier and Payosova (n 169).

556 Arguably, by the acceptance of climate change as a common concern already entails that with respect to the issue no one state has absolute policy autonomy (see chapter $1 \mathrm{pp}$ 3437). Express use of the notion in the trade field would assist the dialogue in clarifying the ambit of interdependent rule making.

557 The importance of such systemic change particularly involving the trade regime was one of the conclusions made in the previous chapter. See p. 76 above. 
place squarely within the classical domain of sovereignty. This clear demarcation through the linkage with Common Concern limits the proposed duty to cooperate only to narrow, critically important areas.

Developing an enhanced cooperation agenda based on the doctrine of Common Concern would require three key steps, i.e. (i) recognition, (ii) coherent rules of action, and (iii) equity and differentiation. Formal recognition of the concept expedites the inclusion of the notion into the body of WTO law. The recognition must thereupon be followed by the creation of an institutional mandate and forum, making a shared understanding of the needs and related responses possible. Lastly, a balance must also be engrained in allocation and apportionment of responsibility between the wто members, incorporating a standard of equitable differentiation. These three steps are elaborated hereunder.

\section{Incorporation through Recognition}

To the extent concerted action in pursuance of a Common Concern is envisaged to take place at the wто, it can only be possible through appropriate agenda-setting at the Ministerial level. An express recognition of the doctrine of Common Concern of Humankind, as well as establishment of a shared understanding of its consequences, creates a basis for the agenda-setting. ${ }^{558} \mathrm{An}$ example can be given of sustainable development. Recognition of sustainable development in the preamble of the Marrakesh agreement enabled the members to set the Doha Development Agenda, which, among others, integrated the notion of mutual supportiveness of the goals of free trade and environmental protection. ${ }^{559}$ Not only would recognition serve the purpose of agendasetting, but bringing Common Concern of Humankind into the folds of the treaty regime of international trade would also allow recourse to the principle for the purposes of interpreting the treaty obligations. ${ }^{560}$

At the end of the day, it is a consensus-building exercise that would be successful only if taken up by the willing state and non-state actors. Repeated claims made on the basis of Common Concern, and proposals for negotiation

$55^{8}$ Common Concern would serve the purpose of establishing an inclusive agenda. On this point, see again, Young ( $\mathrm{n}$ 553) 153. The author notes - '[r] egime interaction during negotiation, implementation and adjudication will be informed by principles that encourage transparency and inclusivity. Such principles recognise that the full range of "interests"- of all those affected by climate change- needs to be incorporated in the meeting of regimes'.

559 Same is true for setting the fisheries subsidies negotiation agenda. 'Doha Work Programme: Ministerial Declaration' (n 468), Annex D, para 9.

$560 \quad$ See Chapter 1 V C at p. 45 and onwards. 
that captures the varying interests of the members are therefore important. In the initial phase, already familiar language such as - "[r]ecognizing that climate change is a common concern of humankind, members shall, therefore, take steps to resolve the concern, namely ..., ${ }^{561}$ can start the process of claims and responses.

\section{Coherent Rules of Action}

Recognition of Common Concern must be followed by defining the perimeter of climate action in the trade regime. This requires a clear articulation of the shared goals, specification of the scope of activities, as well as limits of the incursion of trade rules into the climate domain. In broadest terms, the fundamental purpose of trade cooperation should be to pay due attention to the reality of climate change and the need to take appropriate actions, while taking into account the shared values and agreed goals in that regard. Also important is to set the general terms of interaction between the regimes. It means that within the scope of Common Concern, the climate protection imperative should receive primacy over impartial preservation of market access benefits and strict adherence to non-discrimination. ${ }^{562}$

A shared understanding of the objective further triggers the question of tasks apportionment along two dimensions of governance, horizontal and vertical, in accordance with the principle of subsidiarity. ${ }^{563}$ Horizontal apportionment of tasks need to take place at the international level. Along this dimension, the issue would be the sharing of detailed rulemaking mandate between the trade and the climate regime at the global level. The vertical apportionment concerns the linkage between international and the lower levels of governance. Along that dimension, the principal task would be to create a complementary and interlocked system for sharing the governance function to

561 The language can build upon the expression as contained in the Preamble of the Paris Agreement. One further example is Article 275 of the Free Trade Agreement between the EU, Colombia and Peru. See p. 109 above.

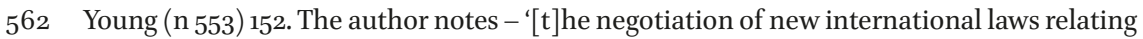
to climate change which have the possibility of interaction with existing laws from other regimes must be attendant to the possibilities and constraints of regime interaction'.

563 IsabelleFeichtner,'Subsidiarity',MaxPlanckEncyclopediaofPublicInternationalLaw (Online, Oxford University Press) <https://opil.ouplaw.com/view/10.1093/law:epil/978019923169o/ law-978019923169o-e1477?print=pdf $>$ accessed 25 October 2020. Subsidiarity is a principle of power allocation found frequently in domestic constitutional law. It is also a growing norm in international affairs. While scholars differ on the meaning of the notion, here it is used as a principle that sets the locus of action at a level of governance or a regime that is the most competent, effective, and proximate to the cause. 
implement the rules that translate the climate responsibility into effective and adequate action. ${ }^{564}$

To the extent removal or reform of market barriers positively contribute to address the Common Concern of climate change, the notion of subsidiarity applied horizontally should dictate that the WTO is not absolved of responsibilities on that front. ${ }^{565}$ Unlike the opposing view maintained by some members as noted in the previous chapter, ${ }^{566}$ subject-matter expertise available at the што necessitates the finding that the organisation is the best platform to guide the power of international trade in addressing the climate change. For example, while conservation and management of marine fisheries resources are contributed to by different international organisations and treaty bodies, the work on regulation and removal of fisheries subsidies is mandated to the WTO.

Effective implementation of any outcome of international cooperation at the WTO would require support from other levels of governance. The essence of vertical subsidiarity in this regard is putting in place a shared and symbiotic relationship between international and domestic law. On one hand, rulemaking at the international level should ensure that ample options exist to suit a state's specific circumstances and interests. On the other hand, domestic actions should ensure that sufficient effort is made to meet the targets set at the global level.

\section{Equity and Differentiation}

In law, the role of equitable considerations is to imbue strict positivistic readings of black-letter rules with contextual considerations of an economic, moral, or developmental character. ${ }^{567}$ In this sense, equity is present in different domestic legal systems, ${ }^{568}$ as well as at the international level. ${ }^{569}$ Equitable

564 Cottier and Hertig (n 117) $320-322$. The authors note that 'transboundary environmental problems do not need to be regulated comprehensively on the global level. [...] International law may prescribe the goal to be reached in terms of $\mathrm{CO}_{2}$ reduction, while it is up to "lower" levels of governance to choose the means to reach that aim and to implement them'.

565 Robert Howse and Kalypso Nicolaidis, 'Enhancing WTO Legitimacy: Constitutionalization or Global Subsidiarity?' (2003) 16 Governance 73, 86-88.

566 See Chapter 2 IV B at pp. 98-99 above.

567 Cottier, 'The Principle of Common Concern of Humankind' (n 7 ) ss 1.3.2.1, \& 1.5.3.

568 Thomas Cottier, 'Equity Revisited: An Introduction', Equitable principles of maritime boundary delimitation: the quest for distributive justice in international law (Cambridge University Press 2015) 9-13; Also, Thomas Cottier, 'Equity in International Law' in Thomas Cottier, Shaheeza Lalani and Clarence Siziba (eds), Intergenerational Equity: Environmental and Cultural Concerns (Brill Nijhoff 2019) <https://brill.com/view/title/3949o> accessed 25 October 2020.

569 Cottier, 'Equity Revisited: An Introduction', ibid 22-24. 
considerations and due regard to different socio-economic conditions remain at the heart of the special and differential treatment standards available under the wTo agreement. ${ }^{570}$ While trade has led to growth, the benefit therefrom does not reach all within and between countries; meaning that the agenda of equity therein remains incomplete.

In this context, it is proposed that any new obligations which are the outcome of trade cooperation for LCT diffusion must balance the states' responsibilities of compliance with their ability to do so. Similarly, homework measures that are adopted in relation to the new cooperation arrangement should also be modulated in their application while taking due account of equitable considerations. This way, incorporation of equity plays a positive role in ensuring inclusivity and participation by all actors, which are themselves common attributes of multilateral climate actions.

A legal context is necessary for the implementation of equity, as in the absence thereof, the notion becomes ambiguous and hence difficult to put into action. ${ }^{571}$ While the doctrine of Common Concern serves as the tool to broaden the ground for applying equity in trade law, the particular legal context is aptly supplied by the principle of common but differentiated responsibility (CBDR). CBDR is a long-standing and dynamic foundational norm of the climate regime, which apportions the burden of climate responsibility among countries having regard to their historic contribution to the problem, as well as different levels of ability to meet the demands. ${ }^{572}$ Reflecting the change in the economic situation of the countries, the nature of the CBDR principle has also changed over time. Initially, under the Framework Convention (i.e. the UNFCCC), CBDR was reflected in a sharp division between the developed (listed in Annex-I) countries and others in terms of mitigation commitments, as well as commitments regarding financial and technological support. ${ }^{573}$ The voluntary nature of the nationally determined contributions (NDC s) under the Paris Agreement largely dispenses with differentiation on the mitigation front, as all countries are equally obliged to commit. ${ }^{574}$ With respect to support provisions, especially finance, differentiation can still be observed, but a specific reference

\footnotetext{
570 ibid 26.

571 ibid 31-34.

572 Bodansky, Brunnée and Rajamani (n 129) 27, 52 .

573 ibid 28 .

574 ibid 219-220, 223-224. The authors call it a model of 'bounded self-defferntiation'. The only exception is the obligation upon developed countries to provide financial support to developing countries for mitigation and adaptation. Article 4.5, read with Article 9.1, Paris Agreement (n 28).
} 
to UNFCCC Annex-I is missing. ${ }^{575}$ These dynamic developments should be taken into consideration at each stage of climate action in pursuance of the Common Concern doctrine, especially when such measures entail costs to other countries. Compliance with the $\mathrm{CBDR}$ is also necessary due to its position as a well-established guiding norm for climate action, which cannot be abandoned simply by switching action platforms at the international level.

Equity and differentiation are the safeguards to maintain a balanced agenda and to prevent the Common Concern doctrine from becoming a tool of value imperialism. ${ }^{576}$ It should not, however, be automatically assumed that a lack of capacity to act, or pressing economic development priorities can altogether excuse governments from any compliance responsibility. Equitable considerations would rather necessitate identification of the capacity gaps and development of support systems for such wTO members.

\section{Cooperation Regarding Low-Carbon Technology Diffusion}

This section portrays how the above-outlined trade cooperation agenda would shape the relationship between trade and LCT diffusion. The previous chapter showcased the differences in the conceptualisation, pursuit, and institutional frameworks regarding technology development and transfer between the climate and the trade regimes. While the soft law based climate regime has witnessed an incremental development in rulemaking, the stricter trade regime has fallen short of making any notable progress. It is proposed that the latter situation be changed by developing a new narrative of trade action, based on the framework of cooperation outlined above. The effort would be initiated by establishing a shared understanding of the key notions, and also by articulating the trade regime's role. The new narrative would be an improvement in terms of its prioritised focus on the diffusion of LCT s, also in terms of creating new opportunities to take empirically informed actions.

\section{A Outline of the Proposal}

The starting point of cooperation for LCT diffusion is a shared belief in the positive contribution of domestic trade policy measures to that effect. The next

575 Bodansky, Brunnée and Rajamani (n 129) 225-226.

576 Peter-Tobias Stoll explains that a doctrine such as Common Concern runs the risk of imposing liberal western values across the board. See, 'Comments: The Doctrinal Approach of Common concern' in Cottier (ed) Prospects of Common Concern in International Law, (Cambridge University Press 2021). 
important point is an agreement among the WTо members endorsing that the deployment and diffusion of LCT s are better facilitated in the existence of an enabling policy environment domestically, as well as globally. Such an agreement is the first step to create a ground of shared understanding, as well as recognition of the relevant rules and principles of the climate regime. Though the creation of necessary policy environment is a domestic prerogative, a global consensus to do so enables the realisation of that target in a complementary, mutually beneficial, and least trade-distorting fashion. Towards this end, trade cooperation at the international level should establish the need to prevent the failure of the markets to adequately spread LCT. Appropriate traderelated measures can contribute to the growth of new technology markets, address the price competitiveness problem, change patterns of production in the manufacturing hubs, reduce consumption emission in the biggest markets, attract further investment in the key sectors, and boost technology outflows. Although a theoretically sound claim, no concrete steps have yet been taken to turn it into reality.

Operating under the responsibility to cooperate arising out of the doctrine of Common Concern, the role of the trade regime, therefore, would be to complement the progress made in the climate regime regarding clean technology diffusion. In this regard, it would be important to reflect the same spirit conveyed through the terms of the technology framework (TF) serving the Paris Agreement. The foundational principles enshrined in the TF are coherence, inclusiveness, a results-oriented approach, a transformational approach, and transparency. ${ }^{577}$ Those should also guide cooperation in the trade regime. The framework identifies the promotion of diffusion and deployment of existing and emerging climate technologies as one of the factors identified for innovation promotion. ${ }^{578}$ The TF also acknowledges the need for market regulation and an enabling policy environment. Furthermore, it is mentioned that the private sector should be made aware of future market opportunities and also be incentivised to participate. ${ }^{579}$ With respect to the enabling environment and capacity building, the technology framework invites governments to take steps to enhance private sector involvement through policy interventions that create "favourable market conditions for climate technologies". ${ }^{580}$ Considered together, the TF supplies the docking point for trade cooperation to feed into

577 Para 3, Technology framework under Article 10, paragraph 4, of the Paris Agreement (n 277).

578 Para 8(c) ibid.

579 See Chapter 2 II A (iii) at pp. 65-66 above.

580 ibid. 
the LCT diffusion goals. Well-functioning markets, healthy competition, and appropriate protection of intellectual property - all contribute to realising an enabling regulatory environment for technology transfer. This includes market mediated transfers, coupled with necessary support mechanisms, which are useful and indispensable complements to the overall efforts to mitigate climate change.

While cooperation to create an enabling environment can be worthwhile even when it is not all-inclusive, broadest possible participation is the most desirable outcome nonetheless. Effective cooperation efforts must at least cover the top emitters, ${ }^{581}$ the big markets, ${ }^{582}$ and countries on the technology frontiers ${ }^{583}$ - all culminating to indicate the special relevance of the G2o nations. Except for any poor, or vulnerable economy, countries belonging in these categories are well-integrated into the global trading system, which shows the potential of trade rules to modify their practices. Moreover, as many of these countries would be middle to high-income ones, they would be more amenable to regulation through trade policy preferences and restriction, compared to promises of financial or other forms of assistance. ${ }^{584}$ The latter is nevertheless an important issue with regard countries specifically vulnerable to climate change impacts. ${ }^{585}$ Ensuring participation by these economies in cooperation is indispensable to retain the legitimacy of the effort. Moreover, it is also important for these countries to have an equal voice in rule-setting.

The substantive content of the proposition can be presented in a simplified 'push-pull' interaction as depicted in Figure 3 below. The main message conveyed here is that trade cooperation for the diffusion of LCT principally involves putting together complementary measures that can be adopted and

581 According to the latest (2014) available data, the ten biggest greenhouse gas emitting countries and regions are, China, United States, European Union (28), India, Indonesia, Russia, Brazil, Japan, Canada, and Iran. Available at www.climatewatchdata.org, accessed 25 October 2020.

582 According to the latest (2017) available data, the ten biggest importing countries are, China, United States, Germany, Japan, France, South Korea, Italy, Netherlands, Mexico and Canada. Available at www.wits.worldbank.org, accessed 25 October 2020.

583 Countries that are at the technology frontier would vary depending on the field of innovation in question. However, as the patent concentration studies cited in the previous chapter showed, quite invariably these are mostly OECD countries with the exception of India, China and Brazil in select areas. For more, see Chapter 2 III A at pp. 77-80 above.

584 As the insights from the CDM projects also shows that some of these countries, e.g. India and China, are more receptive to market-mediated technology transfers in comparison to other developing countries.

585 It is difficult to group a category as such. It should nevertheless include, inter alia, lower income countries, especially coastal and small island states. 
implemented by the parties to the technology-related transactions. From a macro perspective, measures to facilitate clean technology diffusion should primarily focus on two issues. First, in the countries where technologies originate (labelled 'Foreign'), appropriate incentives must be introduced to encourage their outflows to deserving destinations. This is a 'push factor' (number 1) as shown in the figure. Second, countries at the receiving end of the LCT $s$ (labelled 'Home') must create policy arrangements that ease the domestic producers' access to cleaner technology solutions. This is a 'pull factor' (number 2), also a part of the domestic enabling environment at Home. The exact choice of pull measures may depend on the actual market situation and barriers prevalent therein. In addition to the two issues, process and production regulating measures like a carbon tax (number 3) adopted at the major destinations for the Home's exports (labelled Foreign) may further boost the demand for LCT in Home's export-oriented sectors. Side by side, appropriate assistance mechanisms must also be put in place to reflect differentiated responsibility and also to ensure that the trade policy measures in the foreign countries do not unreasonably affect the market access opportunities of the developing nations.

Certain caveats should be duly noted. First is the importance of complementarity. For successfully facilitated clean technology transactions, it is important

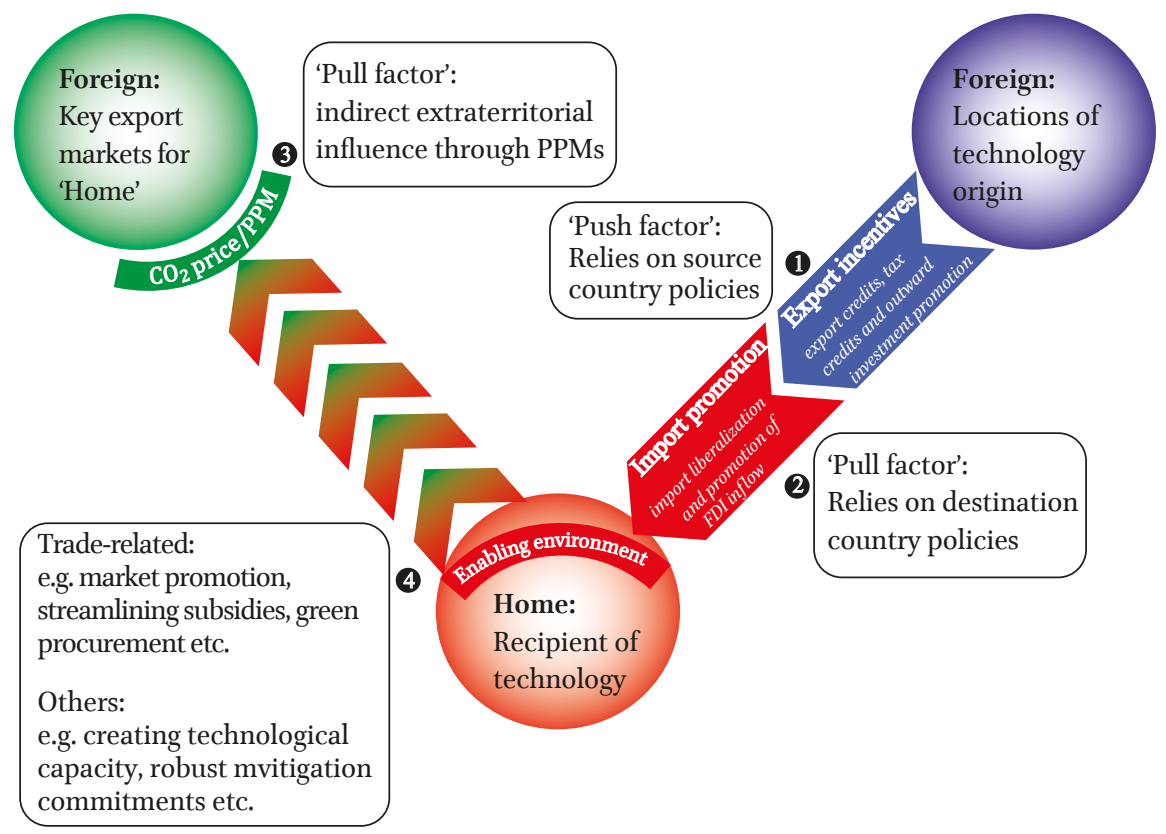

FIGURE 3 Trade-related aspects of clean technology diffusion 
that the 'push' and 'pull' measures are complementary to each other. This goes back also to demonstrate the need for prior cooperation between the parties to establish mutual understanding and commitment to a shared goal. Second, cooperation itself is only the first step, demonstrating the political commitment. It must be followed up by practical measures that are implemented domestically. In the absence of domestic implementation, cooperation alone cannot bring diffusion of LCT s. That is the domain of homework obligations; another aspect of the Common Concern doctrine. Last, reforms of market regulations are but one facilitator for technology transfer. While focusing on the enabling environment and the trade rules, it must also be accepted that other measures beyond the domain of wто laws are also as important for successful transfers of LCT s, e.g. domestic investment on education and training.

\section{B Identifying Actors and Respective Motivations}

The framework above also identifies that trade policy assistance for LCT transactions can arise from different directions- from actors whose motivation to so act may vary to a degree. Two such actors are those that are directly engaged in the commercial transaction leading to diffusion of technology, i.e. the supplier and the receiver. Irrespective of the exact nature of the private transactions (e.g. license agreement, export and import, foreign investment, or public-private partnership), trade policy measures exist that match the motivation of the respective ends. This apart, in cases where the technologies are sought to service export-oriented sectors, demand changes in the large enough consumption market (e.g. processing standard imposed by the EU) can further hasten the suppliers' choice of investment in new solutions.

Suppliers of LCT s: This category of actors would include, but would not exclusively be limited to the handful of locations at the technology frontier. ${ }^{586}$ Firms are in need of innovation that suits their specific circumstances. Any other firm having the necessary solution can be a supplier of LCT. While the suppliers are undoubtedly motivated by the necessity of climate mitigation, but there also are the interests of accessing new markets and revenue growth. Policies that incentivise out-licensing, investment, technology cooperation, as well as trade, are most suited to further trigger the motivation of the suppliers.

Receivers of LCT s: In theory, LCT s are in demand all over the world to keep going 'green'. From a trade perspective, the primary focus of policy should be to influence sectors or locations that are significant sources of GHG emissions due to intensified production and export activities due to being a global

586 See $\mathrm{n}_{583}$ above. 
manufacturing hub (e.g. China), or specific export-oriented activities. For such locations to deploy LCT s, the action ought to make reasonable business sense. More specifically, in these locations, apart from climate change mitigation, the key driving motivation would be securing access to export markets in the longterm. Policy measures that result in a lower cost of the technologies, contribute to creating long-term demand for low-carbon products and secure the firms from competing with polluting alternatives will be appropriate for such regions.

Another equally important category of technology receivers is the poorer countries with development constraints and strong export dependency. These locations cannot, for obvious economic and capacity constraints, undertake too drastic a shift towards clean technologies. It is of utmost importance to make sure that the economic development opportunities of these countries achieved through trade are not unduly constrained. Thus any cooperation scheme at the multilateral level must incorporate support mechanisms that can adequately assist these regions to set out on a low-carbon growth trajectory.

Large consumption/importing markets: These are the large markets (e.g. the US or the EU) serving as export destinations for many countries. Changes in the consumption patterns and regulations in such regions are of utmost importance for reducing carbon leakage, as well as to establish full responsibility for emissions made. Such steps can also create an additional demand-pull that would encourage the suppliers to shift towards cleaner products and production. The focus should remain on the need to reflect changing consumer choices, as well as the shared and differentiated responsibility to address carbon emissions. As consumption regulation measures can easily take a pure protectionist bias, it is important that the Common Concern doctrine draws the limits for their application.

\section{Identifying Relevant Measures}

There are different trade measures that suit particular situations and motivations of the actors and positively contribute to the LCT diffusion in line with the proposed narrative. These measures are themselves not new, but the emphasis on their potentially facilitative role for LCT diffusion is. In light of the foregoing paragraphs, it is contended that the respective position of a country or sectors therein would dictate the type of trade policy measure that should be deployed in any given situation. As a result, when thinking of relevant policy measures, it is prudent not to advocate for a fixed list of options. Instead, we argue that the form and nature of trade-related actions facilitating diffusion of low-carbon technology are context-dependent. ${ }^{587}$

587 For some indication, see, Traerup, Greersen and Kundsen (n 408) 5, 14-18. 
Most of the trade policy measures facilitating clean technology diffusion can be put into either one of the following three categories, i.e. (i) market access reform, (ii) process and production regulation, and (iii) industry-level incentives. In a given circumstance, appropriate measures from one of these categories can potentially boost LCT transactions by positively influencing either the demand or the supply side of the transaction, as well as by boosting related consumption and production. These categories are covered below. Other beneficial measures not falling under any of these categories are mentioned thereafter.

\section{Easier Market Access for Low-Carbon Technology Products and Services}

The dismantling of market access barriers is seemingly the least controversial avenue to augment the trade flow in LCT related goods and services. Unsurprisingly, liberalisation of environmental goods and services (EGS) is a longstanding Doha agenda. ${ }^{588}$ Even so, many developing countries still maintain unbound, or very high bound rate tariff lines relevant to clean technologies. 589 For example, in South Asia, Bangladesh and Myanmar have no fixed upper limits (i.e. the bound rate of duty) on the rates of import tariffs applicable on solar $\mathrm{PV}$ cells (HS854140). In Pakistan, the bound rate of tariff for the same is $50 \%$ ad valorem. ${ }^{590}$ Lower prices resulting from the removal of market access barriers provide dual benefits. It allows interested recipient firms better options and prices for cleaner technology solutions, as well as grants better market access to the relevant suppliers of technology.591

Though easy sounding, easing market access for LCT products has proven to be exceedingly difficult, if not impossible. The key reasons behind the failure to deliver on the Doha agenda on EGS and subsequent stalling of the plurilateral approach are disagreements regarding product coverage and negotiation method. ${ }^{592}$ Scholars also contend that a large group of developing

588 See Chapter 2 IV B (ii) at p. 99 above.

589 David Ockwell and others (eds), 'The Role of Trade and Investment in Accelerating Clean Energy Diffusion: Private Sector Views from South-Asia', Low-carbon technology transfer: from rhetoric to reality (Routledge 2012) 275-277.

590 'Tariff Download Facility: WTO Tariff Data Base' <http://tariffdata.wto.org/Default.aspx> accessed 25 October 2020 .

591 Melendez-Ortiz and Sugathan (n 551) 940-941.

592 Mark Wu, 'The WTO Environmental Goods Agreement: From Multilateralism to Plurilateralism' in Panagiotis Delimatsis (ed), Research handbook on climate change and trade law (Edward Elgar 2016) 285-289; Robert Howse and Petrus B van Bork, 'Options for Liberalising Trade in Environmental Goods in the Doha Round' (International Centre for Trade and Sustainable Development 2006) <https://www.files.ethz.ch/isn/92782/2006_ 07_Options_for_Liberalising_Trade_.pdf> accessed 25 October 2020; ICTSD (n 512). 
and least-developed countries have no export interest in the products under negotiation. ${ }^{593}$ As a result, on one hand, there is a perverse incentive for many members to free-ride without meaningful engagement; 594 and on the other hand, actively engaged members try to maximise benefits by including products of export interest that have very little to do with environmental benefit. 595

When the Doha mandate was framed in the early 2ooos, development and transfer of climate technology was not a top global priority as it is now. As a result, the negotiations did not focus on this aspect. Any future negotiation mandate should take account of the mutual benefits arising from climate technology diffusion, which may then make reaching a balanced outcome easier.

While services are an inseparable component for the deployment of LCT s, there has been no focused discussion on improving market access for the necessary services. The need for such improvement arises from the fact that the components part of the clean technologies are often vertically integrated with a range of services (e.g. design and engineering, construction, sale, maintenance and operation, training etc.). ${ }^{596}$ The difficulty is that there is very little understanding of the extent of the services need in this regard. ${ }^{597}$ Also, the current

593 Mark Wu, 'Why Developing Countries Won't Negotiate: The Case of the WTO Environmental Goods Agreement' (2014) 6 Trade, Law and Development [i]; Fahmida Khatun, 'Trade in Environmental Goods by Least Developed Countries: Issues for Negotiations' (2012) 13 South Asia Economic Journal 157.

594 Wu, ibid.

$595 \operatorname{ICTSD}\left(\mathrm{n}_{512}\right)$.

596 For a broad overview of the relevant services, see, Ronald Steenblik and Massimo Gelosso Grosso, 'Trade in Services Related to Climate Change: An Exploratory Analysis', vol 2011/o3 (2011) OECD Trade and Environment Working Papers 2011/o3 < https://www.oecd-ilibrary. org/trade/trade-in-services-related-to-climate-change_5kgc5wtdgrzw-en> accessed 25 October 2020; For wTo focused discussion, Thomas L Brewer and Andreas Falke, 'International Transfers of Climate-Friendly Technologies: How the World Trade System Matters' in David Ockwell and Alexandra Mallett (eds), Low-carbon technology transfer: from rhetoric to reality (Routledge 2012) 297-298; Thomas L Brewer, 'International Technology Diffusion in a Sustainable Energy Trade Agreement: September 2012' in Gary C Hufbauer, Ricardo Melendez-Ortiz and Richard Samans (eds), The Law and Economics of a Sustainable Energy Trade Agreement (Cambridge University Press 2016) <https:// www.cambridge.org/core/product/identifier/9781316137048\%23AT-app-7/type/book_ part> accessed 25 October 2020 .

597 Neither the guidance documents of the technology needs assessments, nor the process of assessments itself have so far have made any indication in this regard. For some relevant discussion, see, Joachim Monkelbaan, 'Trade in Sustainable Energy Services: October 2013' in Gary C Hufbauer, Ricardo Melendez-Ortiz and Richard Samans (eds), The Law and Economics of a Sustainable Energy Trade Agreement (Cambridge University Press 2016) <https://www.cambridge.org/core/product/identifier/9781316137048\%23CN-bp-3/ type/book_part> accessed 25 October 2020; Olga Nartova, 'Assessment of GATS' Impact 
services classification system does not allow sufficiently exclusive identification of the climate-related services to launch multilateral negotiations. ${ }^{598}$

The earlier mentioned success of the APEC countries in reducing tariffs on a list of environmental products ${ }^{599}$ is an example that shows market access reform can be achieved among a smaller number of participants. While the APEC list is incomplete when it comes to climate technology related products, ${ }^{600}$ it has successfully influenced some other preferential trade agreement (PTA) negotiations. ${ }^{601}$ We assume that an exclusive focus on liberalising LCT or climaterelated products and services based on the Common Concern narrative could be substantially easier to implement within smaller constellations.

It is also possible to explore non-reciprocal ways of easing market access. There is no prohibition against unilateral liberalisation of the domestic market for goods and services of relevance for the LCT s. Also, further examination should be made on whether preferential market access schemes like the GSP+ can introduce preconditions such as adequate emission reduction efforts by the candidate countries .

\section{Regulation of Production Processes and Performances}

Process and production measures, commonly known as PPM s, generally refer to government interventions to influence process and production across borders. ${ }^{602}$ As a category, PPM is broad. It can include varied types of measures which, when deployed by a significantly large importing market, can trigger the uptake of LCT s by the exporting firms. This way, the PPM s allow the importing country to conditionally grant the benefit of its domestic market access, at the same time reflecting fundamental public policy concerns. Some of the prominent tools that fall into the PPM category are taxes, technical regulations, and other forms of preconditions that apply to products' intrinsic

on Climate Change Mitigation' in Thomas Cottier, Olga Nartova and Sadeq Z Bigdeli (eds), International trade regulation and the mitigation of climate change: World Trade Forum (Cambridge University Press 20o9).

598 Mahesh Sugathan, 'Winds of Change and Rays of Hope How Can the Multilateral Trading System Facilitate Trade in Clean Energy Technologies and Services', Clean Energy Technologies and the Trade System: Proposals and Analysis (International Centre for Trade and Sustainable Development (ICTSD), World Economic Forum 2013); Also see, Monkelbaan, ibid; Nartova, ibid.

599 See p. 108 above.

6 oo Vossenaar ( n $\left._{514}\right)$.

601 Melendez-Ortiz and Sugathan (n 551). It was mentioned that some PTA s negotiated by Canada uses the APEC list as basis for tariff reduction.

602 Kateryna Holzer, Carbon-Related Border Adjustment and WTO Law (Edward Elgar 2014) 92-93. 
characteristics or their production methods. ${ }^{603}$ Compliance with the importing country's PPM would therefore enable an exporter to avoid financial costs (e.g. tax burden), or valuable benefits (e.g. licenses or permits for export). Relevant product characteristics related compliance requirements imposed by a PPM can include efficiency or performance standards (e.g. fuel efficiency of a car, or energy efficiency of consumer electronics) ${ }^{604}$ Process requirements could be based on emission footprint standards, or specific processing requirements (e.g. low-emission aluminium smelting methods).

As part of the broader PPM category, technical regulations and standards pertaining to the reduction of GHG emissions can be considered as technologies in their own right. Mandatory technical regulations and certification are important not only to shape demand, but also to overcome the technical barriers by defining new markets for LCT s. Side by side, voluntary standards are increasingly becoming norms rather than exceptions guiding different aspects of sustainability in trading relations between businesses, as well as between businesses and consumers. Delimatsis points out that while so far the voluntary sustainability standards have been slow to incorporate climate change related criteria, such inclusion may prove to be controversial due to the added cost and possible negative impact on poverty reduction resulting from diversion of trade. ${ }^{605}$ The author proposes for the standards schemes to be connected to climate finance mechanisms so that the producers and the suppliers along the value chain can reap benefit from the capacity-building supports. ${ }^{606}$ This would further contribute to clean technology diffusion.

While the appeal of the PPM s regarding technology diffusion lies in the possibility to channel domestic demand and thereby triggering the need for corresponding technology in the production source countries, it leaves a WTO member open to a potential legal challenge. This is especially true for the measures that distinguish based on non-product related attributes (e.g. emission footprint), which according to the current wTо jurisprudence may be

603 For a detailed overview, see, Christiane R Conrad, Processes and Production Methods $(P P M s)$ in WTO Law: Interfacing Trade and Social Goals (Cambridge University Press 2011) $21-56$.

604 For a quick take on the relevance of standardization in different sectors of G HG emission, see, Jorge L Contreras, 'Standards and Related Intellectual Property Issues for Climate Change Technology' (Social Science Research Network 2012) SSRN Scholarly Paper ID 1756283 418-421 <https://papers.ssrn.com/abstract=1756283> accessed 25 October 2020.

605 Panagiotis Delimatsis, 'Sustainable Standard-Setting, Climate Change and the TBT Agreement' in Panagiotis Delimatsis (ed), Research handbook on climate change and trade law (Edward Elgar 2016) 159.

606 ibid 16o. 
considered as discriminatory ${ }^{607}$ Notwithstanding that, there is considerable leeway in finding such measures as compliant with the GATT 1994 and other covered agreements. ${ }^{608}$ With respect to renewable energy, Thomas Cottier proposed that the use of non-product related PPM measures be matched with the related technology transfer support so that the development concerns can be addressed. 609

The next chapter discusses some of these issues in the context of a proposed carbon pricing measure.

\section{Promotion of Trade in Low-Carbon Technologies through Incentives}

Regulation of domestic incentives is important for the diffusion of LCT $s$ in two ways. First, governments can support the domestic commercial entities that enter into low-carbon technology related export or investment transactions with developing country firms by sharing the political or financial risks undertaken (e.g. through official export credit supports). ${ }^{610}$ Such support measures might help to materialise LCT transactions which otherwise would not have taken place. Tax rebates schemes are often provided to domestic industries to be established in new locations. Incentives in equal terms can be provided to invest in low-carbon development across borders as well. ${ }^{611}$ Second, the geographies seeking to attract new technologies can likewise devise specific incentives, e.g. feed-in tariffs (FIT s), to attract foreign investments. With respect to incentivising low-carbon technology transfer to least-developed countries, more could be achieved within the framework of Article 66.2 of the TRIPS.

607 Conrad (n 6o3) 13; Erich Vranes, 'Carbon Taxes, PPMs and the GATT' in Panagiotis Delimatsis (ed), Research handbook on climate change and trade law (Edward Elgar 2016); Steve Charnovitz, 'The Law of Environmental PPMs in the WTO: Debunking the Myth of Illegality' (2002) 27 Yale Journal of International Law 59, 91.

608 Gabrielle Marceau, 'Do PPM Concerns Have a Future' in Denise Prévost, Iveta Alexovičová and Jens Hillebrand Pohl (eds), Restoring trust in trade : liber amicorum in honour of Peter van den Bossche (Hart 2019).

609 Thomas Cottier, 'Renewable Energy and Process and Production Methods' (International Centre for Trade and Sustainable Development (ICTSD), World Economic Forum (WEF) 2015) 5-6.

610 Michael Finus and others, 'International Cooperation: Agreements and Instruments', Climate change 2014: mitigation of climate change: Working Group III contribution to the Fifth Assessment Report of the Intergovernmental Panel on Climate Change (Cambridge University Press 2014) 1035-1036. Chapter 5 of the thesis discusses this option in greater detail.

611 Bernard M Hoekman, Keith E Maskus and Kamal Saggi, 'Transfer of Technology to Developing Countries: Unilateral and Multilateral Policy Options' (2005) 33 World Development 1587, 1593-1594. 
Given the increased developing country interest in domestic supports, as well as the shared commitment to climate responses, it would be quite worthwhile to explore any opportunity to rejuvenate the non-actionable category of subsidies. As argued later, the resurrection of Article 8 in toto may not be the best way possible. ${ }^{612}$ Instead, members should renegotiate the provision to allow measures of direct pertinence to resolve issues of Common Concern, including that of LCT diffusion. With respect to the agriculture sector, there is already scope for supporting farmers with climate-friendly means and methods. To the extent developing and least-developed countries would need access to better farming methods, additional support mechanisms could be developed. Again, the TRIPS Article 66.2 can be of utility for the LDC s in this regard.

Currently, there exist no prohibitions on encouragement of foreign investment, or on subsidisation of services export. While lack of regulation is not good news in itself, as it leaves the markets solely at the will of the parties, this can nonetheless be used as an opportunity to incentivise LCT related investment and services outflow.

Another area of regulation in this regard is to rationalise and reduce incentives that act against the diffusion of LCT s. Such are subsidies provided for fossil-fuel production and prices thereof, supports towards polluting electricity generation, as well as similar infrastructure and generation supports abroad.

\section{Other Areas}

Although market-mediated transfers account for a large part of LCT diffusion across countries, there are also some that due to inherent characteristics do not find themselves in private markets. ${ }^{613}$ Non-market technologies are of a one-off type, i.e. not so frequently transacted as to sustain a private market domestically. For example, power plants, grid infrastructure, and transport management systems would fall within this category. Often governments are the providers of these. Hence public procurement policies can play a role in showing preference LCT s over others.

Apart from that, long-term policy signals are also important to induce technology diffusion. Trade policy, especially when committed through international legal instruments, plays a complementary part to assure the private actors in the market, as well as investors overseas, of a stable and facilitative business environment. Needless to say, other business environment indicators can also play a beneficial role. With respect to LCT, of special significance is

612 More on this in Chapter 5 III B below.

613 Boldt and others ( $\mathrm{n} 55) 710$. 
ensuring that relevant and adequate educational and training opportunities are available to the domestic workforce. These aspects indeed merit a deeper discussion, but they remain beyond the scope of the study.

For the developing country firms moving closer to the technology frontier, access to cutting edge products and solutions can become growingly problematic. It is because the industry leaders may become reluctant to share their intellectual property (IP) due to concerns over competition. Research indeed suggests that there are some key pieces of technology that firms refuse to share. ${ }^{614}$ In such cases, IPR related flexibilities like compulsory licensing can play a role. That apart, there is no general case to be made for deviation from the minimum IP protection standard secured under the TRIPS. ${ }^{615}$ What is more important for technology transfer is a transparent and predictable legal system capable to protect the IPR S of the foreign holders. This is a contributing factor to building long-term trust and thereby boosting the inward flow of LCT s. However, it is also important that effective competition regulation is put in place so that concentrated market power does not result in abusive practices.

\section{A New Balance}

Introducing a new narrative of trade and diffusion of LCT, especially one that calls for the undertaking of positive responsibility, requires striking a new and careful balance along several dimensions.

One factor is to delimit the domain of the Common Concern inspired narrative within the trade regime. Informed by the notion of horizontal subsidiarity, the operational mandate of the WTO with respect to clean technology diffusion has to be precisely drawn. With the helpful hint from the technology framework (TF) as agreed by parties in the Paris Agreement, the reach of the institutional intervention of WTO in this regard would go no further than necessary for trade rules to make a direct and positively beneficial contribution to clean technology diffusion. ${ }^{616}$

Another aspect of the balance concerns the implementation of specific trade policy measures through domestic actions. While good faith trade cooperation devolves upon all states as a shared responsibility, the principle of differentiation would suggest that actions following the outcome of cooperation

614 See for example the study of Watson and Byrne on the experience of the Chinese firms in Chapter 2 III B at p. 83 above.

615 This is extensively addressed in Chapter 2 III A above.

616 Although, there can theoretically be other Common Concern inspired mandates to tackle other aspects of climate change through trade related responses. Any such additional areas would also be delimited in the same fashion. 
be conditioned upon the ability, as well as the availability of support. For the LDC s in particular, the homework responsibility should therefore be made conditional upon their receiving necessary support. That apart, the developing countries can be granted relatively more policy room to incentivise their domestic firms' adoption of LCT s. Such an approach would make it easier to find an agreement among stakeholders in different situations.

Furthermore, to put in place an economic policy environment conducive to the diffusion of LCTS, it is also important that there is a degree of complementarity between steps taken by different actors themselves, and also between the trade regime and others on the whole. For example, successful technology diffusion would be achieved when sectors or technologies incentivised from one side meet with complementary promotions from the other side. Similarly, incentivising growth of clean technology-based industries needs to be met with removal of support from the fossil-based energies and sectors. Overall, it should be kept in mind that trade measures would complement the TF and not supplant it.

\section{E Ensuring Compliance}

In theory, the proposed narrative for technology diffusion should be mutually beneficial and therefore should not draw any significant compliance challenges. However, if cooperation is not achieved, or if one or few significant polluters do not cooperate, the doctrine of Common Concern would call for, also legitimise, unilateral imposition of trade restrictions by the counterparts. ${ }^{617}$ In cases where unilateral countermeasures are being considered, it must be made sure that the non-cooperation is wilful (based on mala fides) and not arising out of true capacity constraints. Also on the part of the countries taking measure, such a step must come subsequent to attempts at a conciliatory settlement between the parties. This point is elaborated at length in the last chapter of the book.

\section{Implementing the New Approach}

\section{A Overcoming Political Inertia}

At the outset, it must be admitted that the key practical challenge to putting the proposed narrative into operation is overcoming the apparent political inertia in the multilateral trading system. The doctrine of Common Concern

617 Cottier, 'The Principle of Common Concern of Humankind' ( $\left.\mathrm{n}_{7}\right)$. 
proposes to overcome this challenge by suggesting further responsibility be assumed by states. However, as discussed in the first chapter, this normative aspect of the doctrine requires more support in the form of affirmative state practice to achieve unquestionable legal salience. Though the initiation of state practice itself is hardly a matter for legal enquiry traditionally, legal scholars, as we also noted in the first chapter, highlight from time to time the dialectical process of the emergence of new legal norms through repeated practice. ${ }^{618}$ What can nevertheless be said is that the important next step for the doctrine of Common Concern to overcome the political inertia is 'norm entrepreneurship', as termed by Finnemore and Sikkink. ${ }^{619}$ It means that the interested state and non-state actors ${ }^{620}$ need to take the vanguard position in putting the proposition into operation. Countries that take the lead in domestic trade-related climate action (e.g. the European Union), can be expected to do the same with respect to LCT diffusion. The accumulation of political will to engage with the proposed technology diffusion narrative can speed up if demands to that effect come from the non-state actors (e.g. the different citizens' movements). ${ }^{621}$ The potential economic benefits of the proposed arrangement would also work to that effect. Importantly, the fundamental thrust behind the Common Concern based argument for LCт diffusion is that the benefits arising therefrom are shared by all irrespective of their geographic locations. This brings the proposed cooperation narrative to the domain of a positive-sum game.

For the willing political actors, operating under the precept of Common Concern as a basis of action can provide additional legitimacy support. Any such action taken would, in a reflexive fashion, accord legal salience to the doctrine, and through that to the proposed narrative of clean technology diffusion. In addition, engagement of the trade regime in relation to broader common interests will also contribute to the output legitimacy of the WTO. On the opposite side, outright refusals to engage in good faith discussions and consensus-building to facilitate LCT diffusion under the framework of Common Concern should be seen as unbecoming of the responsibilities of a sovereign actor and therefore illegitimate.

618 See Chapter $1 \mathrm{v}$ C above.

619 Finnemore and Sikkink (n 199).

620 Bacchus terms it as 'the willing', James Bacchus, The Willing World: Shaping and Sharing a Sustainable Global Prosperity (Cambridge University Press 2018).

621 See, for example, 'Act Now' (Extinction Rebellion) < https://rebellion.global/about-us/> accessed 25 October 2020 . 


\section{B Tasks at the Multilateral Level}

The experience with the environmental goods negotiations at the wTO has aptly taught that even seemingly easy multilateral cooperation can be very fraught in practice. Nevertheless, for reasons outlined earlier, ${ }^{622}$ cooperation is most beneficial when it takes place at the multilateral level. To reiterate in brief, only through multilateral cooperation is it possible to take full account of the varied stakeholder interests, potentially resulting in a truly shared understanding of LCT diffusion and the related parameters of coordination between the climate change and the trade regimes. On the same note, institutional coordination between the WTO and the UNFCCC at specific issue levels is impossible in the absence of a multilateral initiative. Compared to regional cooperation, multilateral engagement should be preferred by the developing countries, because otherwise, the standards of differential treatments may suffer the chance of being omitted out of any agreed outcome. ${ }^{623}$

First, the Wто members must recognise the need to act to prevent climate change, based on the doctrine of Common Concern. Such recognition, as noted earlier, is best done through a Ministerial declaration. The declaration should expressly mention that climate change is a common concern of humankind and therefore the members have a responsibility to adopt and implement necessary trade-related measures. It must further be noted that against the backdrop of a mutually supportive trade and environmental rules, the special situation of climate as a common concern begs for positive steps to be taken within the trade regime. Such actions should be complementary to the attainment of the goals embedded in the Paris Agreement. Noting the positive impact trade policy can have on various areas of climate action, the members shall cooperate to facilitate those outcomes while being aware of the special situation of the developing and least-developed members. The Hong Kong ministerial declaration on fisheries subsidies can be instructive in this regard. ${ }^{624}$

622 See section II at p. 127 above.

623 One can note the experience of the multilateral environmental agreements in this regard, which played a crucial role in mainstreaming the differentiated responsibility norm.

624 Annex D, 'Doha Work Programme: Ministerial Declaration' (n 470) para 9, holding "recall our commitment at Doha to enhancing the mutual supportiveness of trade and environment, note that there is broad agreement that the Group should strengthen disciplines on subsidies in the fisheries sector, including through the prohibition of certain forms of fisheries subsidies that contribute to overcapacity and over-fishing, and call on Participants promptly to undertake further detailed work to, inter alia, establish the nature and extent of those disciplines, including transparency and enforceability. Appropriate and effective special and differential treatment for developing and least-developed Members should be an integral part of the fisheries subsidies negotiations, taking into account the 
The next step is to put in place operational rules that would provide the substantive content and extent of a member's responsibility to act to facilitate diffusion of LCT s. Within the Wто legal framework, substantive rulemaking can take different avenues (e.g. partial amendments of the existing rules, plurilateral or multilateral agreements, time-limited specific waivers, peace clauses etc.). ${ }^{625}$ The best possible approach would be for the members to create a negotiation mandate and a platform to develop new rules facilitating the diffusion of climate technology. Until an agreement is reached and has become applicable for all members, possible illegality of any trade measures demonstrated to promote LCT diffusion within the Common Concern framework shall be waived. ${ }^{626}$

To specify the subject-matter of cooperation, it is possible to have an emission sector-focused approach (e.g. energy, transport, agriculture, industry, waste etc.), or a trade-issue specific one (i.e. liberalisation, PPM s, incentives, differential supports, and other issues). A sector-focused approach would allow dealing with the full spectrum of trade-related concerns across the different covered agreements pertaining to the chosen sector. ${ }^{627}$ This would unlock more possible combinations while exchanging concessions and therefore may ease finding of an agreement. The attractiveness of the other option, i.e. a trade-issue focused agenda lies in its simplicity, as it will keep the negotiation agenda linear and thereby cut down on complexity. It would also have the advantage of familiarity, as the members' representatives and the institutional expertise are attuned to tackle the questions in a trade-issue specific manner. Moreover, as each of the trade-related questions neatly belong to specific covered agreements, subsequent integration of any outcome would be relatively easier.

importance of this sector to development priorities, poverty reduction, and livelihood and food security concerns;".

625 For a comparative discussion on each of the avenues in the context of clean energy technologies, see, Amelia Porges and Thomas L Brewer, 'Climate Change and a Renewable Energy Scale-Up: Responding to Challenges Posed to the WTO', Clean Energy Technologies and the Trade System: Proposals and Analysis (International Centre for Trade and Sustainable Development (ICTSD), World Economic Forum 2013).

626 Article IX:3 and Ix:4, Marrakesh Agreement Establishing the World Trade Organization (n 226); Porges and Brewer, ibid $56-57$.

627 For a similar proposition, see, Thomas Cottier and Donah Baracol-Pinhão, 'Environmental Goods and Services: The Environmental Area Initiative Approach and Climate Change' in Thomas Cottier, Olga Nartova and Sadeq Z Bigdeli (eds), International trade regulation and the mitigation of climate change: World Trade Forum (Cambridge University Press 2009). 
A question may nevertheless arise regarding the method of integrating the substantive outcome with the covered agreements. Though this is a question that is better left to the nature of the ultimate outcome, a few observations are warranted here. Any negotiated reduction in tariffs can be appended to the GATT schedule of commitments or as a separate plurilateral agreement. Other issues like the PPM question can be resolved by agreeing to an interpretative understanding. Where the issue would be a shortcoming in one of the WTо covered agreements (e.g. the agreement on subsidies), amendment of the existing provisions or inclusion of new ones will be the solution. There may also be issues that may advance the ongoing work agenda at the wTO. One such is the discussion on a better classification of services to facilitate market access negotiation under the GATS. Progress in that regard can be finally subsumed in the agreement as well.

Furthermore, current coordination between the WTO and the UNFCCC secretariats needs to be deepened. With respect to LCT, upcoming work in the climate regime under the supervision of the technology executive committee (TEC) has elements that are of much relevance to the wTO. An understanding should be struck between the TEC on one hand and the WTO secretariat under the committee on trade and environment (CTE) leadership on the other. The understanding should cover mutual information and expertise sharing, coordination of tasks, as well as sub-delegation and co-working, if possible. In the same vein, the mandate of the working group on trade and technology transfer (WGTTT) should be reformulated with specific emphasis on trade-related climate technology diffusion issues. Recommendations by the WGTTT on ways to remove LCT diffusion obstacles can open new paths towards cooperation.

It is important that the development concerns find adequate attention in the process of negotiations. However, development should not be an excuse to shield the major emitters from making significant, effective commitments. This would be counterproductive. The focus should rather be on identifying the constraints that the countries face and the nature of assistance that could be provided to tackle those. Of course, the developing countries' responsibilities would be conditional upon the provision of the necessary support. With special regard to the LDC s, arguably, Article 66.2 of the TRIPS Agreement already supplies a robust platform for incentivising technology transfer. However, the performance of the developed countries' obligation under that provision could be better guided so that the climate-related technology needs are taken into special account. The language of this provision can be connected to the identified technology needs and the nationally appropriate mitigation actions (NAMAS) by the LDCs, which can then be advanced to the developed country 
parties for finance or other incentives. Comparable mechanisms should also be devised for developing countries in need of support.

While some of these tasks can arguably be undertaken under the current Doha negotiation mandate (e.g. goods and services market liberalisation), it would be optimal to draw up a new trade and climate negotiation agenda comprised of the proposals made here. As political feasibility is the wall between the optimal and the real, in all probability, a few of the prioritised issues must make the cut. Willing states should find in the Common Concern-based cooperation agenda a balanced approach worth investing in.

\section{Incorporation in Preferential Trade Agreements (PTAs)}

The preferential trade agreements (PTA s) serve not only as labs for the willing states to try out new commitments with limited participation but they also pave the way for the inclusion of emerging issues, as well as their subsequent multilateralisation. ${ }^{628}$ Outside the shadow of the WTO, the PTA s are the next best option to generate trade cooperation regarding diffusion of LCT s. The PTA s can serve as platforms for technology-related experience and information sharing, involve non-state actors, as well as test a range of market reform measures (e.g. removal of fossil fuel subsidies, or easing market access). Modern PTAs can hypothetically include commitments regarding facilitation of cross-border investments in LCT s- something beyond the reach of the WTO.

Benefits apart, PTA s have structural limitations as well. Issues of interest covered in the PTA s would tend to be narrowly tailored to the interests of the parties. This is a challenge to subsequent multilateralisation of the contents of such agreements. Also, some issues, e.g. institutional coordination, are inherently multilateral and cannot be addressed in a PTA setting. It should also be noted that apart from preferential market access, the PTAs cannot legitimise any other actions in contravention of the wTо laws (e.g. export subsidies for LCT).

That being mentioned, the best examples of progress made through the PTA s so far are the agreements between liberal trade partners that are also willing to combat climate change. For instance, agreements signed by the European Union with its like-minded partners provide the best available examples of treaty language regarding trade and climate cooperation. The EU-Colombia-Peru agreement has already been mentioned for its formal

628 James Bacchus, 'On Making and Remaking Enabling Frameworks for Sustainable Development', The willing world: shaping and sharing a sustainable global prosperity (Cambridge University Press 2018) 374-376. 
endorsement of climate change as a common concern of humankind by the parties. ${ }^{629}$ The agreement between the EU and Singapore saw the parties be open to the possibility of "cooperation on trade-related aspects of the current and future international climate change regime, including ways to address adverse effects of trade on climate, as well as means to promote LCT s and energy efficiency". ${ }^{630}$ The recently concluded Comprehensive Economic and Trade Agreement (CETA) between the EU and Canada also advances similar cooperation language. ${ }^{631}$ The CETA provides an opportunity to consult with the non-state actors. ${ }^{632}$ Such opportunities are ideal for advancing the narrative currently proposed. As the forerunners, these countries should explore ways of further strengthening their PTA commitments with respect to climate action.

\section{Domestic Actions}

As the narrative has demonstrated, the efforts ultimately boil down to facilitative trade measures taken for climate technology diffusion at the domestic and sub-state levels. There is a significant difference between such actions taken against the backdrop of effective international cooperation, and otherwise. In the first scenario, a large part of the domestic action is an implementation of the agreed international arrangement, the terms of which are determined by the nature of the actor, the action in question, and the particularities of the domestic legal system. Depending on those factors, actions can vary from liberalisation to export promotion, or from improvement of the business environment for the relevant industries to the adoption of PPM s. In the second situation, i.e. in the absence of a legitimising background of an international legal framework, a duty to act in response to the common concern of climate change nevertheless exists. But as it is not woven into the structure of trade law, any trade measure taken in pursuance of common concern may be difficult to justify. Therefore, in the absence of cooperation at the international

\footnotetext{
629 See Chapter 2 IV D (ii) at p. 109 above.

630 Article 12.10 (f), EU - Singapore free trade agreement.

631 The parties envisage cooperation to extend on "trade-related aspects of the current and future international climate change regime, as well as domestic climate policies and programmes relating to mitigation and adaptation, including issues relating to carbon markets, ways to address adverse effects of trade on climate, as well as means to promote energy efficiency and the development and deployment of low-carbon and other climate-friendly technologies;", Art 24.12, sub 1(e), Comprehensive Economic and Trade Agreement (CETA). In 2018, the CETA joint committee issued a recommendation to cooperate towards promotion of the objectives of the Paris Agreement.

632 Articles 24.7 and 24.12, sub 3, ibid.
} 
level, domestic actions, probably carried out only by the willing parties, would put those parties under a disproportionate burden.

As a last resort, the Common Concern doctrine is open to the possibility of unilateral countermeasures to elicit adequate actions from the non-compliant trading partners. It would be important to pay due regard to the expression 'last resort' before one summarily dismisses the proposition. We echo an earlier statement that this option is not proposed as a response against capacityconstrained actors, or those that must prioritise economic development over everything else. Putting aside the reasonable causes of variable compliance, one would see the kernel of realism that is embedded in this proposition. It is important that the opportunity to impose trade-related countermeasures exists against the blatant dismissal of the necessity of action, or blunt denials of the facts on climate change. While previously such propositions were labelled as yet another developed country ploy, it should be noted that with the change of that traditional narrative, the developed countries (e.g. the United States) would also find themselves in the crosshairs. ${ }^{633}$

\section{Conclusion}

This chapter has outlined a new trade cooperation narrative to guide the reform of the што rules and domestic trade policies for the benefit of LCT diffusion. We portrayed here that trade measures have not only restrictive but also facilitative aspects, which can be put to use for the diffusion of clean technology. Furthermore, the deployment of trade measures need not necessarily affect climate commitments. The regimes can continue to retain their respective structural and operational uniqueness. Nevertheless, the same values of climate action can be animated in both systems. The Common Concern of Humankind doctrine can guide the trade regime in such a way that it contributes to the fulfilment of climate targets.

At the heart of the narrative is a responsibility to effectively cooperate within the trade regime, founded upon the doctrine of Common Concern. The contributory and complementary role of trade policy measures is often overlooked in the climate literature as the latter tend to highlight the use of trade tools only as a vehicle for delivering threats of sanctions. This chapter advanced that the Common Concern doctrine based cooperation framework can be used to drive forward a novel, empirically informed, and dedicated narrative for the

633 Mattoo and Subramanian ( $\mathrm{n}_{534}$ 21-24; Simon (n 528 ). 
diffusion of LCT s. To implement that in practice, the chapter has outlined a 'push-pull' framework, also identified the relevant sets of actors and measures therein. While cooperation should ideally take place in a multilateral setting, it is also the most difficult to do so at that level. Easier, in comparison, is cooperation among a smaller constellation of actors, e.g. in a PTA setting. The chapter suggests that more and stronger steps be taken along those avenues.

Appropriate domestic measures are what eventually carry the day. Therefore, the chapter further suggests that given the available policy options and the particular situation of a country, the cooperative outcome must further be implemented through suitable actions at different levels of domestic governance. However, keeping in mind the tenets of equity and differentiated responsibility, due care must be taken to account for the special situations of developing and least-developed countries. While this would not exempt the countries from adopting necessary measures, respective actions must be met with adequate support. 